\title{
TRANSPLANTE DENTAL: REVISÃO DA LITERATURA E RELATO DE CASO
}

\author{
TEETH TRANSPLANTATION - REVIEW OF LITERATURE AND CASE REPORT
}

\begin{abstract}
RESUMO
Introdução; O objetivo do tratamento odontológico é a manutenção da dentição natural com saúde e função durante a vida do paciente. Este trabalho discute a possibilidade da utilização de transplantes dentais autógenos como opção de reabilitação oral, através da apresentação de um caso. Método: O procedimento de transplante dental envolve a extraçáo do dente doador, preparo do alvéolo receptor, posicionamento do dente transplantado, sutura e contenção temporária. Resultados e conclusóes: Os resultados obtidos confirmam a possibilidade de sucesso estético e funcional com os transplantes dentais autógenos.
\end{abstract}

DESCRITORES: Reabilitação bucal • Dente não-erupcionado • Transplante autólogo.

\section{ABSTRACT}

Introduction: The goal of dental treatment is to maintenance of the natural dentition health and function during to patient's lifetime. This paper discusses the possibility of autogenous dental transplantations as treatment option and reports a case. Methods: The transplantation procedure involves extraction of the donor tooth, preparation of recipient socket, positioning of donor tooth, suturing, and temporary splinting. Results and conclusion: The results confirm the possibility of a successful esthetic and functional treatment with autogenous teeth transplantation.

DESCRIPTORS: Mouth rehabilitation • Tooth, unerupted • Transplantation, autologous.

\footnotetext{
* Residente em Cirurgia e Traumatologia Bucomaxilofacial do Complexo Hospitalar Padre Bento de Guarulhos

** Chefe do serviço de Cirurgia e Traumatologia Bucomaxilofacial do Complexo Hospitalar Padre Bento de Guarulhos

*** Professor Responsável pela Disciplina de Periodontia da Universidade Federal de Alfenas - (UNIFAL) MG.

**** Professor Titular da Disciplina de Estomatologia da Universidade Estadual de Montes Claros - (UNIMONTES)

***** Mestre e Doutorando em Periodontia da Faculdade de Odontologia de Piracicaba - (FOP) Unicamp
} 
Giancristófaro M, Paulesini Júnior W, Ribeiro Júnior NV, Martelli Júnior H, Silva CO. Transplante dental: revisão da literatura e relato de caso. Revista de Odontologia da Universidade Cidade de São Paulo 2009 jan-abr; 21(1): 74-8

\section{INTRODUÇÃO}

O termo transplante é usado genericamente para representar a transposição de tecidos biológicos em suas diversas formas $\left(\mathrm{Ely}^{4}, 1965\right)$. Dentre as possíveis modalidades de execução, o transplante dental representa uma manobra cirúrgica em que o dente a ser transplantado é submetido a uma avulsão do seu local de origem e implantado em outro alvéolo natural ou preparado cirurgicamente (Cuffari e Palumbo ${ }^{3}$, 1997).

O transplante dental pode ser: autógeno, quando doador e receptor constituem a mesma pessoa; homógeno, realizado entre diferentes indivíduos, porém da mesma espécie; e heterógeno, realizado entre membros de espécies diferentes (Andreasen ${ }^{1}$, 1981; Clokie et al. ${ }^{2}, 2001$ ).

A maior prevalência na realização de transplantes autógenos ocorre do terceiro molar para o lugar do primeiro ou segundo molar; de pré-molares para o lugar de incisivos e de caninos impactados para sua posição funcional (Andreasen ${ }^{1}, 1981$ ).

Verifica-se com frequência a perda de primeiros molares permanentes em adolescentes, geralmente devido a cáries extensas e/ou lesóes endodônticas. Isso ocorre muitas vezes, pela crença de que esse dente ainda faz parte da dentição decídua e o devido cuidado é, então, omitido (Souza ${ }^{10}$, 1996).

O transplante dental autógeno, comparado a outras formas de reabilitação oral, apresenta as vantagens de evitar alteraçóes no desenvolvimento da maxila e da mandíbula e representar um tratamento conservador, com a possibilidade de desenvolvimento do osso alveolar na área receptora (Gil e Pereira ${ }^{5}$, 1997; Cuffari e Palumbo $\left.^{3}, 1997\right)$. Assim, observa-se que o transplante dental autógeno apresenta-se como uma alternativa eficaz de reabilitação oral, quando bem indicado, podendo ser realizado em sessão única ou em duas etapas. Além disso, constitui-se em um método viável pelo índice de sucesso e custo relativamente baixo, comparado aos métodos tradicionais de reabilitação, como implantes osseointegrados (Clokie, et al. ${ }^{2}$, 2001).

O objetivo deste trabalho é apresentar o acompanhamento radiográfico de um caso clínico de transplante dental autógeno, realizado em sessão única, em uma paciente adolescente, como alternativa terapêutica aos demais métodos tradicionais de reabilitação oral, utilizados rotineiramente na clínica odontológica.

\section{DESCRIÇÃO DO CASO CLÍNICO}

Paciente T.R.C., 14 anos, sexo feminino, leucoder- ma, foi encaminhada à clínica odontológica da Universidade Federal de Alfenas (UNIFAL-MG) com queixa de "mobilidade dental e nódulo gengival" no primeiro molar inferior esquerdo.

No exame clínico intrabucal, verificou-se a presença de fístula na região gengival vestibular do dente 36, na altura da bifurcação. $\mathrm{O}$ dente em questão, quando submetido ao teste de sensibilidade, não respondeu. A avaliação periodontal mostrou presença de sangramento à sondagem, lesão de bifurcação grau II, além de mobilidade dental. As demais áreas da mucosa bucal, assim como a avaliação sistêmica da paciente, apresentaramse normais. $\mathrm{O}$ exame radiográfico periapical mostrou a presença de extensa radiolucidez em toda a área da bifurcação, com suspeita de perfuração endodôntica no assoalho da câmara pulpar e presença de reabsorção óssea acentuada em ambas as raízes dentais (Figura 1), o que contraindicaria condutas do tipo pré-molarização ou rizectomia.

Diante das características clínicas e radiográficas, foi planejada a remoçáo do dente 36 e subsequente transplante autógeno do dente 38. Na Figura 2, observa-se que o dente 38 possuía tamanho compatível com o alvéolo do primeiro molar, além de apresentar rizogênese incompleta, favorecendo o prognóstico do transplante. Optou-se pela realização do transplante em sessão única.

\section{Procedimento cirúrgico}

A antisepsia bucal foi realizada com bochecho de digluconato de clorexidina 0,2\% (Proderma Farmácia de

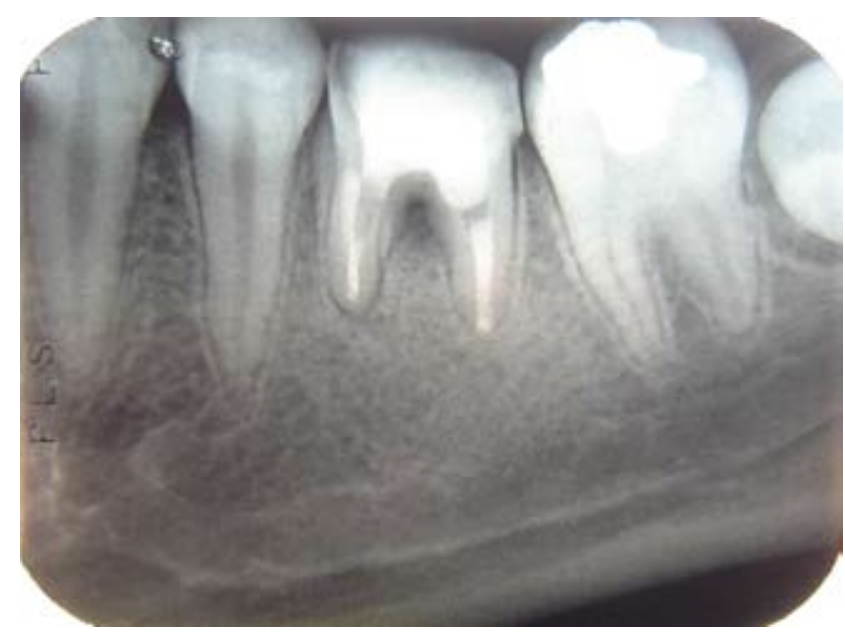

Figura 1: Dente 36 apresentando extensa lesão de bifurcação e raizes curtas devido à reabsorção. 


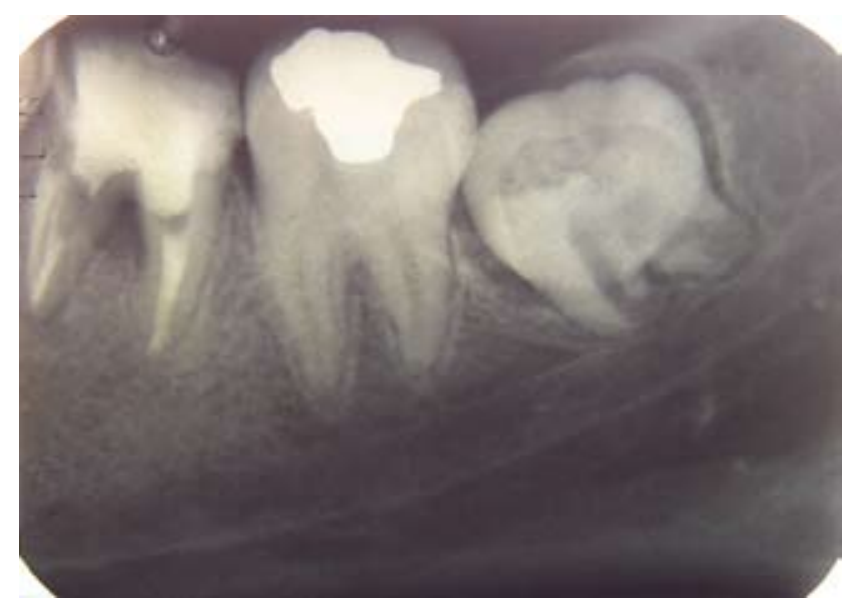

Figura 2: Dente 38 apresentando tamanho compativel com o leito receptor entre os dentes 35 e 37 e rizogênese incompleta.

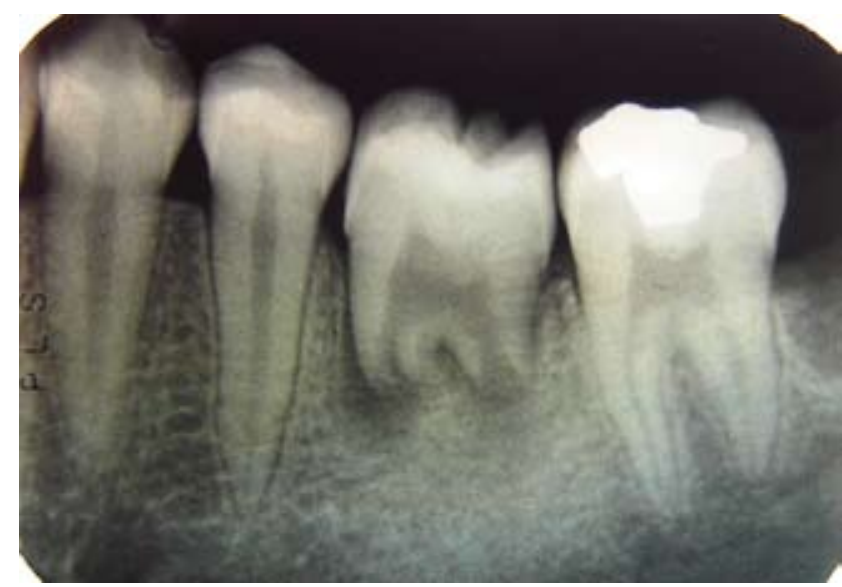

Figura 3: Aspecto radiográfico imediatamente após o transplante dental.

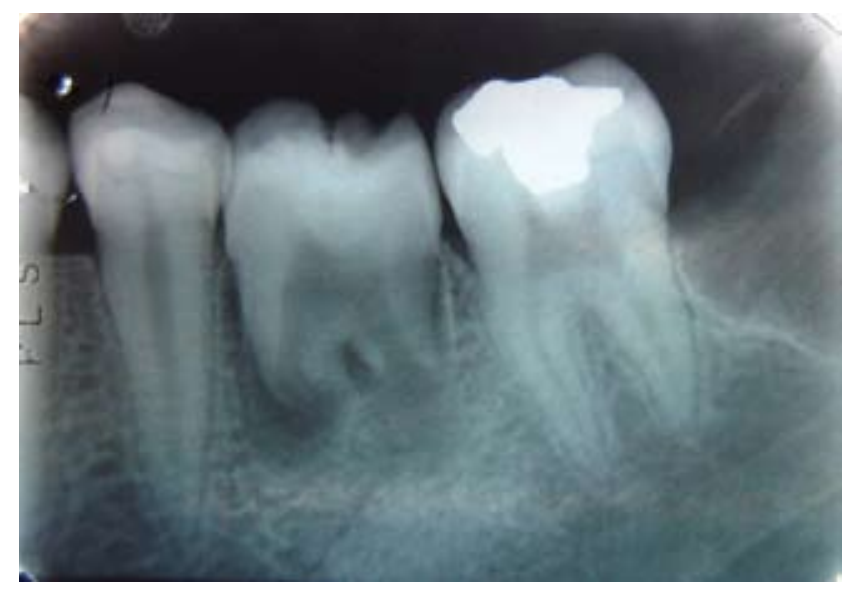

Figura 4: Aspecto radiográfico 30 dias após o procedimento cirúrgico, demonstrando início da neoformação óssea ao redor das raizes de dente transplantado.

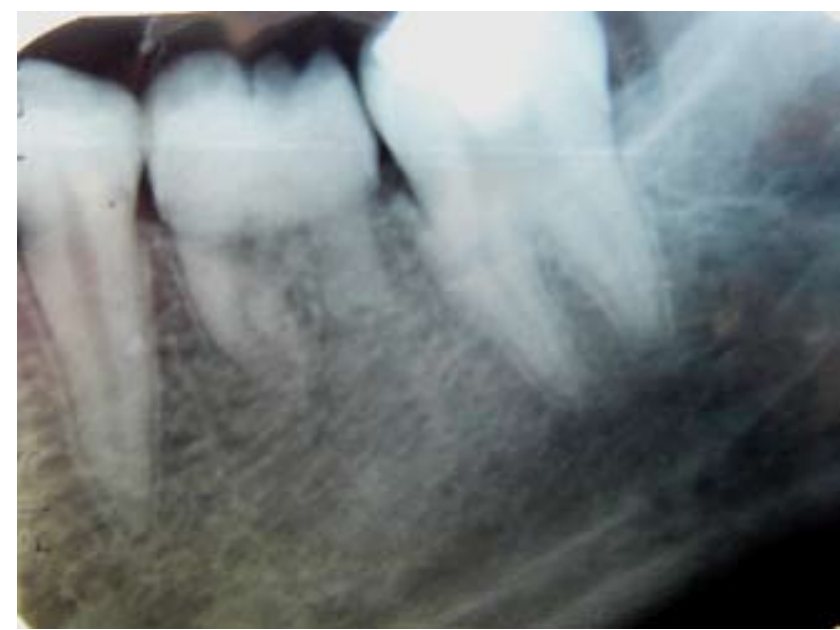

Figura 5: Acompanhamento radiográfico 1 ano após a realização do procedimento cirúrgico do transplante, com formaçáo óssea tanto no leito doador como no leito receptor.

Manipulação Ltda., Brasil) por um minuto, seguindo-se anestesia troncular pterigo-mandibular (Lidocaína DFL Indústria e Comércio Ltda., Brasil).

Inicialmente, realizou-se a extração do dente 36 com intensa curetagem da loja óssea e concomitante irrigação com solução fisiológica. $\mathrm{O}$ alvéolo receptor foi preparado com instrumentação rotatória utilizando-se a broca Three Spade Drill 5mm (3i Implant Inovations, EUA), compatível com as dimensóes do dente doador. Em seguida, realizou-se a remoção do dente 38 com ampla osteotomia para facilitar a extração e minimizar o trauma cirúrgico. $\mathrm{O}$ terceiro molar, após extraído, foi adaptado ao alvéolo receptor, permanecendo fixado através dos contatos proximais, o que se observa pelo aspecto radiográfico imediato (Figura 3).

A contenção do dente transplantado foi realizada com isobutilcianoacrilato (Isodent; Hellma - Brasil). Fez-se o teste de oclusão, verificando-se que o dente estava em infraoclusão. Realizou-se, então, sutura do tipo interproximal com ponto simples, utilizando-se fio de seda 3-0 (JP Indúsria Farmacêutica S/A; Brasil).

A medicação pós-operatória constou de bochechos com clorexidina $0,12 \%$, duas vezes ao dia, durante duas semanas, vibramicina $100 \mathrm{mg}$ uma vez ao dia por 10 dias e paracetamol $750 \mathrm{mg}$ de $6 / 6 \mathrm{~h}$ durante $24 \mathrm{~h}$.

\section{Período de avaliação}

Dez dias após o procedimento cirúrgico, a sutura foi removida e clinicamente constatada uma normalidade 
Giancristófaro M, Paulesini Júnior W, Ribeiro Júnior NV, Martelli Júnior H, Silva CO. Transplante dental: revisão da literatura e relato de caso. Revista de Odontologia da Universidade Cidade de São Paulo 2009 jan-abr; 21(1): 74-8

gengival em relação ao contorno, coloração e ausência de infecção. Duas semanas após o transplante, foi removida a contenção e observou-se normalidade dos tecidos moles e do dente transplantado.

A paciente foi avaliada semanalmente no primeiro mês, quando se observou o aspecto radiográfico 30 dias após o procedimento cirúrgico (Figura 4). A avaliação continuou sendo realizada no primeiro trimestre com intervalos de quinze dias, sendo que no segundo mês foi realizado o teste de mobilidade dental, mostrando-se negativo e o teste de sensibilidade, no qual o dente respondeu positivamente. A partir desse período, a avaliaçáo passou a ser realizada mensalmente até se completar um ano, quando se verificaram a reparação clínica e radiográfica dos tecidos periodontais e a correta adaptação do dente transplantado ao leito receptor (Figura 5).

\section{DISCUSSÃO}

Transplantes dentais autógenos ou autotransplantes representam a transposição dental realizada no próprio indivíduo e foram primeiramente citados na literatura odontológica por Widemam, em 1915, com o transplante de caninos impactados $\left(\right.$ Souza $^{10}, 1996$; Clokie $e t$ al. ${ }^{2}$, 2001).

Algumas manobras na realização dos transplantes autógenos apresentam-se conflitantes na literatura, como a realizaçáo de tratamento endodôntico nos dentes transplantados. $\operatorname{Moss}^{7}$ (1968) afirma que a terapia endodôntica deve ser adotada mediante evidências de alteraçóes apicais, pois a realização da mesma antes ou após o transplante autógeno aumenta a susceptibilidade à reabsorção. $\operatorname{Rios}^{8}$ (1993) indica o tratamento endodôntico no pós-operatório se houver sintomatologia clínica de necrose pulpar, alteraçóes inflamatórias periapicais e reabsorçóes internas e/ou externas progressivas. No presente trabalho, não se verificou qualquer alteração clínica ou radiográfica que suportasse a necessidade da realização do tratamento endodôntico.

Outro aspecto importante na realização dos transplantes autógenos e a contenção dental. Para Grandini et al. ${ }^{6}$ (1989), a contenção tem a finalidade de estabilizar o dente em sua nova posição e possibilitar o reparo dos tecidos pulpar e periodontal. Andreasen ${ }^{1}$ (1981) mostra que o dente transplantado deve retornar às suas funçóes o mais breve possível, pois o estímulo funcional pode prevenir ou eliminar a ocorrência de anquilose, impedindo alteraçóes das fibras do ligamento periodontal. Além disso, o tempo prolongado de fixaçâo estaria diretamente relacionado ao aumento da reabsorçáo radicular. A contenção deve ser mantida pelo período de duas semanas e pode ser rígida ou semi-rígida. Grandini et al. ${ }^{6}$ (1989) relatam que a contenção rígida, promovendo uma completa imobilidade dental, estimula a reabsorção dental, concluindo assim que a fixação semi-rígida parece não interferir negativamente no ligamento periodontal, fator preponderante no prognóstico dos transplantes.

Em relação à revascularização pulpar do dente transplantado, ela depende do estágio da rizogênese e da amplitude do canal radicular, da distância entre a câmara pulpar e o suprimento sanguíneo da parede óssea alveolar e da boa difusão plasmática (Saad Neto e Callestini ${ }^{9}$, 1991).

A proservação do dente transplantado deve ser realizada, segundo Cuffari e Palumbo 3 (1997), após quarenta e oito horas e semanalmente no primeiro mês. Depois, mensalmente até o primeiro trimestre. Em seguida, realizada por dois semestres e, por último, anualmente até a rizogênese completa.

A mobilidade dental deverá ser testada a partir do segundo mês após o transplante. $\mathrm{O}$ dente deve apresentar a mesma coloração inicial; a gengiva marginal e as papilas não devem apresentar alteraçôes morfológicas ou patológicas, devendo estar corretamente posicionadas em relação ao dente transplantado.

\section{CONCLUSÃO}

Analisando o caso apresentado, conclui-se que o transplante dental autógeno representa uma importante alternativa de reabilitação oral. Quando corretamente indicado, o índice de sucesso é grande e permite devolver as características estéticas e funcionais ao paciente. 


\section{REFERÊNCIAS}

1. Andreasen JO. Interrelation between alveolar bone and periodontal ligament repair after replantation of mature permanent incisors in monkeys. $J$ Period Res, 1981 Mar; 16(2): 228-35.

2. Clokie CM, Yau DM, Chano L. Autogenous tooth transplantation: an alternative to dental implant placement ?. J Can Dent Assoc 2001 Feb; 67(2): 92-6.

3. Cuffari L, Palumbo M. Transplante de germe do terceiro molar. Jornal Bras Odontol Clín 1997 mar-abr; 1(2): 23-7.

4. Ely JF. Cirurgia plástica, São Paulo: Fundo Editorial Procienx, 1965.

5. Gil JF e Pereira VSS. Transplante dental autógeno: uma opção terapêutica. Jornal Bras Odontol Clin 1997 mar-abr; 1(2): 5-10.
6. Grandini SA, Barros VRM, Navarro NV. Avaliação clínica de alguns métodos de contenção empregados em reimplantes e transplantes dentais autógenos. Rev Odontol USP 1989 out-dez; 3(4): 469-501.

7. Moss JP. Autogenous transplantation of maxillary canines. J Oral Surg 1968 Dec; 26(12): 775-83.

8. Rios CHN. Transplante dental autógeno de terceiros molares. Rev Científica Cenbios 1993 nov; 1(2): 16-23.

9. Saad Neto M, Callestini EA. Transplante dental: novas perspectivas no transplante dental, relato de caso clínico. Revista da APCD 1991 mai-jun; 45(3): 485-8.

10. Souza JG. Transplante autógeno de germe do terceiro molar inferior para o alvéolo do primeiro molar inferior. Odontólogo Moderno 1996 abr-jun; 23(2): 27-8.

Recebido em: 21/05/2007

Aceito em: 16/07/2008 